\title{
Study on the Conflict Management Process Applied in the Construction of Integrated Transportation Hub Project
}

\author{
SHUSHENG XU1, a, ZHICHAO XU \\ 11. Tianjin University, Tianjin 300372, China \\ 2 Tianjin Rail Transit Groups Co., Ltd, Tianjin 300384, China \\ axss_1016@126.com bgichon@163.com
}

\begin{abstract}
Keywords: conflict management process, integrated transportation hub, fuzzy set theory.
Abstract: According to the trait of Integrated Transportation Hub that it involves amount of stakeholders, dissevering the conflict management process will result in describing conflict inaccurately and keeping the conflict unresolved. Regarding of integrating the quantitative and qualitative approaches, we consider that resolving conflict needs pluralistic model to support. In accordance with the perceived level of the conflicts in Integrated Transportation Hub, the paper used fuzzy set theory to put forward conflict management process and elaborates on its content and application, which would help smooth the conflicts between different stakeholders and achieve the goal of minimizing the possibility of conflict.
\end{abstract}

\section{Introduction}

The reason of poor coordination of integrated transportation hub is that the conflicts between the function design of transportation hub and the use of resources were not tackled properly. The improper treat with the conflicts will make the final performance lower than the expectation [1].In recent years, with construction scale of Integrated Transportation Hub expanding, the broadening scope of stakeholder leads the conflicts among different stakeholders to be various and complicated. Therefore, the attention of scholar to conflict management in integrated transportation hub rises rapidly. Their purpose is to find conflict resolution approaches to guarantee the desirable project performance, which undoubtedly is changeling task for the conflict managers [2].

However, the researches on conflict analysis and resolution mostly focused on deepening the study rather than establishing conflict resolution process [3][4][5]. The process from conflict analysis to conflict resolution is broken. The integrated transportation hub as a complicated and large-scale public project involves numerous stakeholders. Consequently, the requirement of stakeholders should be the beginning of conflict analysis while establishing the conflict resolution mechanism is the key to study the conflict management in integrated transportation hub.

In regard to the issue mentioned, the paper put forward the whole conflict management process comprising "conflict identification-conflict analysis-conflict resolution" by integrating conflict management methods at every stage. The finding of the study makes the conflict manager build the blueprint for resolving conflicts from global perspective and will provide application value in practice.

\section{The Concept and Classification of Conflict In Integrated Transportation Hub Project}

The Concept of Conflict in Integrated Transportation Hub Project. Conflict occurs whenever disagreements exist in a social situation over issues of substance or whenever emotional antagonisms create frictions between individuals or groups. Project conflict is opposition or friction caused by the disputes among different objectives and disharmony in the complicated interpersonal relationship[6]. Project conflicts have the common features of general conflict. Before the stakeholder theory was invented, project conflict was mainly on the disputes among "time, quality and cost". This conflict analysis structure could not deal with the benefit conflict among stakeholders in the project, hence there exists the limitation. In 2004, PMI emphasized that "It is important to identify and manage stakeholders in the project for guarantee the successful completion of the project[7]." Identifying and 
managing stakeholders correspond to the characteristics of strong externality of stakeholders in the integrated transportation hub.

The distinction between the integrated transportation hub project and general project is that the externality of the first one is more distinctive. Some stakeholders in the integrated transportation hub project like passengers, environment protectors, media and so on are out of project manager's control. Therefore, the different requirements of stakeholders at different stages enhance the complicity of project completion, and increase the possibility of conflict happening. Based on the analysis above, the conflict in integrated transportation hub project can be identified as the frictions because internal and external stakeholders with vested interest has different requirements in integrated transportation hub project.

Classification of Conflict in Integrated Transportation Hub Project. The classification of conflicts in Integrated Transportation Hub Project is usually determined by differentia among different objectives or position of different stakeholders in the integrated transportation hub project[8]. Sutterfield, Stroud, Blackwellpointed out that conflict is divergence which includes interpersonal divergence, task divergence and process divergence[9]. J.Ding divided conflicts into conflicts between personal benefits and project benefits, conflicts among different organizations in the project and conflicts between project benefits and social benefits [10].

Based on the conclusion of literature review, the paper classified the conflicts as conflicts on expected utility, conflicts on investment and cost, and conflicts on expected function among the stakeholders in the integrated transportation hub.

\section{Identification of Conflicts In Integrated Transportation Hub Project}

The paper found three main stakeholders in the intricate network of stakeholders by literature analysis. They are government, passengers and hub operation company [11][12]. The relationship of the three main stakeholders is as shown in Figure 1.

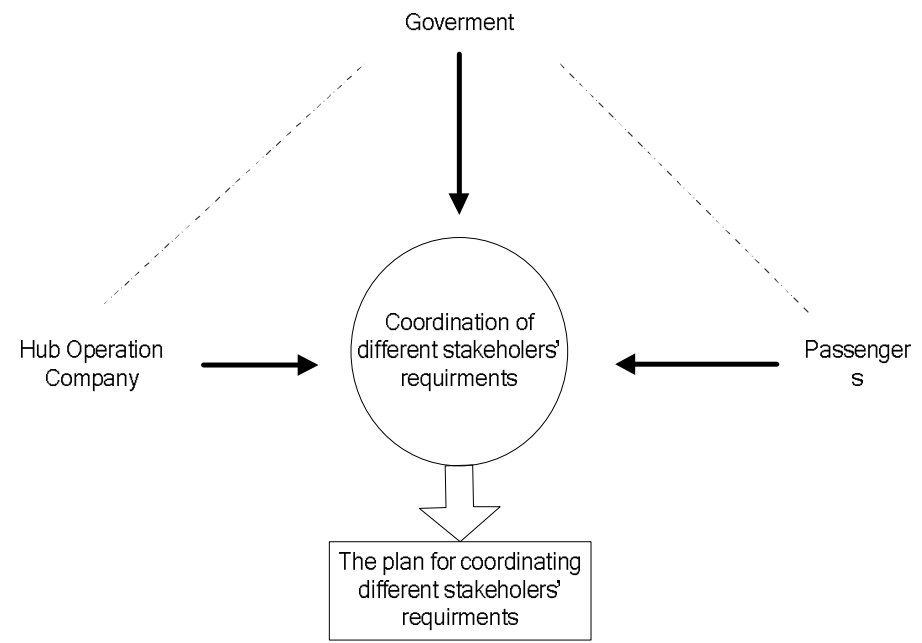

Figure1 The Relationship of The Three Main Stakeholders

According to the field survey and analysis of stakeholder's requirements, the study found three kinds conflicts among the main stakeholders. They are the interest conflicts between government and passengers, the conflicts between operation company and passengers, as well as the conflicts between operation company and government. The following passages will elaborate the three kinds of interest conflicts.

The Conflicts between Government and Passengers. In the construction process of integrated transportation hub, the requirement of the majority of passengers concentrated on the hub function, such as facilitating transfer of waiting, the relatively relaxed environments of transit. However, the government considers that the construction of the integrated transport hub should not only satisfy the transport function, but also should drive the economic development in the surrounding area. That is, the more the government considers the construction of integrated transportation hub is based on the 
perspective of the urban development strategy. Therefore, the interest difference above formed conflict between the passengers' function requirement and government's urban development strategy.

The Conflict between Operation Company and Passengers. The transfer efficiency of the integrated transportation hub is the key indicator for passengers' to evaluate the hub system transportation capability. The improvement of transfer efficiency requires operation company to improve the equipment and services. However, the improvement of equipment and services would inevitably enhance operation company's cost and difficulty of management. The conflict between passengers' function requirement and operation company's budget constraint should be tackled.

The Conflict between Government and Operation Company. Because integrated transportation hub is quasi-profit infrastructure, operating income cannot meet the expenditure of day-to-day operational activities. Under this condition, if effective government policy subsidy mechanism cannot be guaranteed, the operation company will not be able to get enough operating expenses to maintain normal hub operation management, resulting in lower operational efficiency. However, government is also afraid that operation company asks for more than the real needs of the policy of subsidies, which would result in waste of resources. Therefore, how to ensure the subsidy satisfying the need for operation and to avoid the subsidy wasted is the game between government and operation company.

\section{Analysis Of Conflicts In Integrated Transportation Hub Project}

In the paper, set $\mathrm{U}(1,2,3)$ represented the stakeholders, while 1 represented government and 2 represented passengers and 3 represented operation company. Set A (a,b,c) represented the conflicts, while a represented the conflict in allowance, and b represented conflict in transfer space, and c represented conflict in transfer inefficiency. The conflicts situation is as shown in Table 1.

Table 1 Conflicts Situation

\begin{tabular}{|c|c|c|c|}
\hline Conflicts & $a$ & $b$ & $c$ \\
\hline 1 & -1 & 0 & +1 \\
\hline 2 & 0 & -1 & +1 \\
\hline 3 & +1 & +1 & -1 \\
\hline
\end{tabular}

+1 represented agreement, -1 represented disagreement, 0 represented waiver

According to the fuzzy set theory[13], Conflict of stakeholders can be considered as a distance. The greater the distance is, the more intense the conflict is. The paper established a function for calculating the distance and set a threshold for the intensity of conflict which can identify the relationship of the stakeholders.

dis $\tan c e(a, x, y)$ can be identified as:

$$
\operatorname{distance}(a, x, y)=\left\{\begin{array}{cc}
0 & a(x)=a(y)=0 ? \quad x=y \\
1 & a(x) a(y)=0 ? \quad a(x) a(y \\
2 & a(x) a(y)=-1 ? \quad x y
\end{array}\right.
$$

Therefore, the distance sum of conflict $\mathrm{A}$ between $\mathrm{X}$ and $\mathrm{Y}$ can be identified as

$\gamma B(x, y)=\left\{\sum d_{a}(x, y) \mid \operatorname{dis} \tan c e(a, x, y)\right\}$

The conflict function of conflict A X and Y can be identified as

$$
\rho B(x, y)=\frac{\sum_{a \in B} d_{a}(x, y)}{2|B|}
$$

According to the formula (1), (2) and (3), we can obtained 


$$
\rho(1,2)=0.5, \rho(1,3)=0.83, \rho(2,3)=0.67
$$

The conflict matrix is as shown in Table 2.

\begin{tabular}{|c|c|c|c|}
\hline \multicolumn{5}{|c|}{ Table 3 Conflict Matrix } \\
\hline $\mathrm{U}$ & 1 & 2 & 3 \\
\hline 1 & & & \\
\hline 3 & 0.5 & & \\
\hline
\end{tabular}

In this study, the threshold was set as 0.5 . Therefore, the relationship between government and passenger is neutral and the relationship between government and operation company as well as the relationship between operation company and passenger are conflict.

\section{RESOLUTION OF CONFLICTS IN INTEGRATED TRANSPORTATION HUB PROJECT}

The study adopted third party consultant approach for conflict resolution. Based on the analysis of conflicts in integrated transportation hub project, the paper provided three conflict resolution schemes after several meeting among delegates of stakeholders and the third party consultant.

The resolution scheme for conflict between government and stakeholders. Under resource constraints, the government should take the shortest distance as the goal to determine the indicators of hub design. The government is requested to design specific units responsible for carrying out the hub transfer design. So that, the design could not only satisfy the passengers' requests for convenience, but also meet the need of government to realize the value of the integrated transport hub project, which make both parties reach consensus.

The resolution scheme for conflict between operation company and passengers. According to the third party' evaluation for the hub, the operation company should take transfer efficiency at the first place and implement measures for promote stakeholders' convenience. The action of operation company could ultimately coordinate the interests of the hub operators and passengers.

The resolution scheme for conflict between government and operation company. The paper suggested that the government should combine direct subsidies, indirect subsidies and cross subsidies for the hub operation company to provide finance guarantee for sustaining operation of integrated transportation hub. The scheme resolved the interest conflict between government and operation company.

\section{Conclusion}

Integrated transport hub project conflict management process is conflict management framework including conflict-related factors at all stages. In this process, a variety of different approaches integrated with each other, which constitute a system comprising conflict identification, conflict analysis and conflict resolution. The system could support the integration process from qualitative analysis to quantitative analysis more effectively. The use of quantitative and qualitative analysis provided an accurate basis for the conflict control decision-making, so that the requirements of the stakeholders can arrive at consensus, which would help achieve the goal of minimizing the possibility of conflict.

\section{Reference}

[1]Sampo Tukiainen,Kirsi Aaltonen, Mervi Murtonen(2010). "Coping with an unexpected event-Project managers' contrasting sensemaking in a stakeholder conflict in China".International Journal of Managing Projects in Business, Vol.3,No.3, pp.526-543.

[2]Mei-yung Leung,Anita M.M. Liu,S. Thomas $\mathrm{Ng}(2005)$. "Is there a relationship between construction conflicts and participants' satisfaction?" Engineering, Construction and Architectural Management,Vol 12,No.2,pp.149-167. 
[3]Chih-Yao Lo, Yu-Teng Chang and Hsiu-Yu Hsies(2010). "Analysis of Negotiation Strategies on Conflict Resolution with Action Game". International Conference on Intelligent Control and Information Processing. Dalian, China. pp. 13-15, August, 2010.

[4]Séamus A. Power(2011). “Towards a Dialogical Model of Conflict Resolution”. Psychology \& Society, Vol.4,No.1,pp:53 - 66.

[5]Haiyan Xu, KeithW. Hipel, D. Marc Kilgour, Ye Chen(2010). "Combining strength and uncertainty for preferences in the graph model for conflict resolution with multiple decision makers".Theory and Decision, Vol.69,No. 4,pp:497-521.

[6]Gary Barnes,Stephanie Erickson(2005). "Developing a Simple System for Conflict Management of Public Involvement". Transportation Research Record: Journal of the Transportation Research Board.pp:109-113.

[7]Project Management Institute(2004).A Guide to the Project Management Body of Knowledge, PMBOK 3rd edition[M]. PMI, Newtown, Square, PA.

[8]Yilin Yin, Hu Jie(2006). "Study on the Success Criteria of Public Project Based on the Core Value of the Stakeholders". China Soft Science, No.5, pp. $149-155$.

[9] J. Scott Sutterfield, Shawnta S. Friday-Stroud,Sheryl L. Shivers-Blackwell(2007). "How NOT to Manage a Project: Conflict Management Lessons Learned from a DOD Case Study". Institute of Behavioral and Applied Management,Vol.8,No.3,pp: 218-230.

[10] Jie Ding(2010). “ A Study of Construction Project Conflict Management Based on Evolutionary Game Theory”. Modeling Risk Management in Sustainable Construction. pp:321-326.

[11] Yilin Yin, Yao Wang(2009). "Research on Facility Optimization Design of City Transport Hub Project Based on Stakeholders Requirement". Journal of Beijing Institute of Technology(Social Sciences Edition), Vol.11, No.3, pp:53-57.

[12] Yilin Yin, Wenxue Wang(2008). "On Management of the Stakeholders of Tianjin Transportation Hub Project ”. Urban Mass Transit,Vol.11, No.9,pp:4-6.

[13] Pawlak, Z(1998). "An inquiry into anatomy of conflicts". Journal of Information Sciences, No.109, pp:65-78. 